Dossier. Roberto Hozven. "Patrimonialismo y casuismo, puerto y ‘santiaguinería’, en las crónicas ensayísticas de Joaquín Edwards Bello".

\title{
PATRIMONIALISMO Y CASUISMO, PUERTO Y 'SANTIAGUINERÍA', EN LAS CRÓNICAS ENSAYÍSTICAS DE JOAQUÍN EDWARDS BELLO ${ }^{1}$ HERITAGE AND CASUISM, PORT AND 'SANTIAGUINERÍA', IN JOAQUÍN EDWARDS BELLO ESSAYISTIC CHRONICLES
}

\author{
Roberto Hozven \\ Pontificia Universidad Católica de Chile \\ rhozven@uc.cl
}

RESUMEN: Desarrollo este estudio en dos partes. En la primera, estudio las formas del género ensayístico (actitud recesiva e intrusa) determinantes de los contenidos y enunciación del discurso cronístico de Joaquín Edwards Bello. El corpus de análisis son las 3006 páginas de los cuatro volúmenes de crónicas de Edwards Bello, seleccionadas y recopiladas por Roberto Merino. Enseguida, basándome en estudios sobre el patrimonialismo y el casuismo (R. Morse, O. Paz, M. Góngora, Cl. Véliz, C. Stoetzer, etc.), demuestro la vigencia de estas dos instituciones sociales, políticas e ideológicas coloniales en el mundo y sociabilidad chilenas de la primera mitad del siglo XX, tal como las critica Edwards Bello. Consulto bibliografía crítica de Gabriela Mistral, Héctor Soto, Leonidas Morales y Marina Alvarado.

En la segunda parte, demuestro que la crítica de Edwards Bello al patrimonialismo y el casuismo vigente en la sociabilidad chilena del $X X$, se sirve de recursos oníricos, fantasiosos (el fantasma psicoanalítico) y deconstructivos (proxemia, heterología). Con ellos, Edwards Bello no confunde la pluralidad de sentidos de sus crónicas con verdades hipostasiadas. Enseguida, su crítica de "fantasmas" sigue un derrotero antitético. Valparaíso y sus ciudadanos, ciudad en transformación constante en su modernidad astral, se opone a un Santiago conventual, con súbditos coloniales ("la santiaguinería"), que es mausoleo de esqueletos triásicos enclavado en un paisaje cordillerano de espanto. Esta antítesis ("base de mi literatura" —declara) entre ciudades y ciudadanos/ súbditos da vida plural a su crítica ensayístico-cronista.

PALABRAS CLAVE: patrimonialismo, casuismo, ensayo-crónica, fantasma, santiaguinería, porteño

ABSTRACT: This paper is divided in two parts. In part one, the chronicle discourse of Joaquin Edwards Bello is studied under the scope of recessive and intrusive intersubjective attitudes, proper of the essay genre form. I consider that these two intersubjective attitudes determine the contents and enunciation of his chronicle discourse. The corpus analyzed are the 3006 pages comprising the four volumes of Edwards Bello's chronicles, selected and compiled by Roberto Merino. Critical bibliographies of Gabriela Mistral, Hector Soto, Leonidas Morales and Marina Alvarado on Edwards Bello's literature have been consulted for this. Presently, based on research on patrimonialism and casuistry (R. Morse, O Paz, 
M. Góngora, Cl. Véliz, C. Stoetzer, etc.), the prevalence of these two political, social and ideological colonial institutions in the Chilean reality and social discourse in the first half of the twentieth century, as criticized by Edwards Bello, is demonstrated.

The second part proves that Edwards Bello's criticism of the patrimonialism and casuistry that prevailed in the Chilean social discourse of the first half twentieth century uses dreamlike, fantastical (the psychoanalytic fantasme - as understood by Lacanian literature) and deconstructive (proxemics, heterology) resources. Thanks to them, Edwards Bello does not confuse the plurality of meanings in his chronicles with hypostatic truths. Next, his criticism based on these fantasmatic approaches follows an antithetical course. Valparaiso and its citizens, a city in constant transformation because of its astral modernity, oppose a conventual Santiago with colonial subjects (the "santiaguinería"), both of them buried in a mountain range landscape of horror, which is a mausoleum of Triassic skeletons. These antitheses ("the basis of my literature", as he declares) between a modern Valparaiso/a colonial Santiago and their respective citizens/subjects render varied life to his essayistchronicalist plural criticism.

KEYWORDS: patrimonialism, casuistry, chronicle-essay, phantom, santiaguinería, Porteño

Recibido: 15 de febrero de 2020

Aceptado: 21 de mayo de 2020

\section{Patrimonialismo y casuismo en el discurso cronístico-ensayístico de JEB}

JEB (1887-1968) — señorito por su origen gran burgués, escritor reprendedor de la sociabilidad de su tiempo por su oficio periodístico - retrata críticamente en su escritura las prácticas $^{2}$ sociales de las dos instituciones que rigen, una, la gobernanza jurídicopolítica y religiosa de la sociedad chilena e hispanoamericana y, la otra, su tradición cultural desde la Colonia a hoy en día. Me refiero, por una parte, a la institución patrimonialista inmanente a nuestras costumbres, símbolos y usos. Patrimonialismo sintetizó Paz - es "la fusión de lo privado y lo público; el príncipe o el presidente manejan los asuntos colectivos como si fuesen los de su casa" (469). El "clientelismo", , de hoy en

\footnotetext{
${ }^{2}$ Las maneras de operar, de actuar de los hombres dentro de su marco histórico. Las actividades sociales concretas, conscientes y/o inconscientes de los seres humanos cuando interactúan día a día en una comunidad. Las prácticas cumplen, replican, activan y transforman a las praxis: las normas que establecen el marco simbólico e institucional que establece y fija los límites de la realidad histórica donde se realizan actos y pulsiones humanas (de Certeau xi. Lévi-Strauss 192-193, 235).

${ }^{3}$ Cuando el poder sobre las decisiones del aparato administrativo del Estado se utiliza para obtener beneficio privado. El patrón - sea directamente un funcionario u otra persona dotada de suficiente poder como para influir sobre los funcionarios - toma decisiones que favorecen a sus clientes, y que estos compensan con la perpetuación en el poder del funcionario implicado o de su entorno. La relación puede fortalecerse mediante
} 
Dossier. Roberto Hozven. "Patrimonialismo y casuismo, puerto y 'santiaguinería', en las crónicas ensayísticas de Joaquín Edwards Bello".

día, es la extensión transversal de esta manera de operar al gobierno de la administración del Estado, de los partidos políticos, de las instituciones y empresa privada. La otra institución criticada por JEB es el casuismo, el discurso cultural por el qué asimilamos, ordenamos y enunciamos las prácticas de las primeras; el conjunto de reglas preexistentes que subsumen y conforman nuestra experiencia vivida según un universo moral de protocolos (de Bien, de Justicia, de Belleza) anteriores a cada acción concreta (Cariou 213). Domingo Melfi, contemporáneo estimado de JEB, llamó a ambas con el chilenismo "majamama".

Escribí "señorito" porque JEB "no se entiende sino a partir de su superioridad de clase, de su mirada entre irónica y despectiva a los usos de la sociedad de su tiempo", a la seguridad que le proporcionaron sus viajes, los que lo hicieron ser “cien veces más mundano y mil veces más leído que cualquiera de los próceres de su tiempo”. Así calificó “en el corto listado de la gente protegida por la ventaja o el privilegio de redes sociales extendidas" (Soto 335). Desde este mirador de clase y de talento auto-afirmado ${ }^{5}$, JEB reprende los vicios patriarcales de "nuestro viejo Chile" ${ }^{6}$ en una escritura que asume la forma de un gran fresco ensayístico, aunque trizado en la diversidad de géneros en que criticó el patrimonialismo y el casuismo. Sobre todo en sus caudalosas crónicas ${ }^{7}$ (escribió

la amenaza de utilizar esa misma capacidad de decisión para perjudicar a quienes no colaboren con el sistema. (Clientelismo político. Web. 22/ 11/2017. Wikipedia. 15/ 12/ 2017).

4 "[G]elatina de componendas, turbia y elástica, incolora, insípida, sin orientación..." (25), "reparto de puestos, sentimentalismo dulzón, trazado de curvas para no herir intereses, bolsicos donde encajar canonjías" (47).

5 "Ud. y yo pertenecemos a la clase alta chilena y cuatro majaderos dijeron que en esa clase no puede existir talento. Nosotros hemos hecho el Milagro. Naciendo cerca del Club de la Unión, que es el punto más absurdo del planeta, tenemos talento" - escribe JEB a Vicente Huidobro en 1922 (Carta de JEB a Vicente Huidobro, citada por Alvarado. Web). Autoconciencia reconocida dos veces por su sociedad: Premio Nacional de Literatura 1943, y de Periodismo 1959.

6 "Hijo más reprendedor de su padre no le nació a nuestro viejo Chile, satisfecho y sentado en sus prestigios" (Mistral 9).

7 Todas caben — creo- dentro de la definición genérica que elabora Carlos Monsiváis, para la crónica mexicana escrita entre la Independencia y 1968. Género periodístico citadino que sigue la siguiente pauta: "remplaza el idioma letrado (incomprensible a simple oído) por los rumores de la ciudad y de sus calles". "Reconoce republicanamente la vitalidad del habla popular, recrea lo que surge "de abajo"". De este modo, su "registro fugaz de la experiencia cotidiana", en cuanto "cultura dominada", "eleva los hábitos sociales al rango de lo idiosincrático". Por lo mismo, vive críticamente en el ámbito doméstico "la nostalgia de lo desconocido, del suceso insólito de París, Londres, Berlín o New York"; mientras en la ciudad hispanoamericana, "con fastidio, se 'da vuelta a la noria"”. (31-35, 56-77). Agradezco al Dr. Miguel Morales Pulgar la mención y préstamo de este estudio fundamental de Monsiváis sobre la crónica mexicana, que es, al mismo tiempo, un estudio sobre el género en cuanto tal. 
más de diez mil entre 1921-1968) ${ }^{8}$, en las que concentraré este estudio; enseguida, en sus novelas, biografías y otros escritos de las que, en esta oportunidad, prescindo.

Sostengo la primacía del estilo ensayístico en sus crónicas porque en ellas priman dos rasgos fundamentales del discurso del ensayo. Primero, JEB escribe de modo recesivo. Sus afirmaciones refluyen cuestionando lo que las origina, incluyen en filigrana una interrogación sobre lo que acaba de decir. Incluso sus énfasis se transforman en interrogantes, en extrapolaciones que reculan la actitud subjetiva del hablante hacia apartes, márgenes, que sospechan reticencias del sujeto escribiente ante sus propias ideas. Estas interrogantes pueden ser propias, las de su círculo comunicativo; como otras, las de quienes disienten de su propio círculo. Nos hace preguntarnos dónde empieza la ficción y dónde acaba la realidad, rasgo primordial de la crónica (Menéndez y Pelayo 228). Su escritura acusa recibo de sus reticencias y nos involucra en ellas porque su actitud inquisitiva, dialogante, nos hace leerlo como si estuviera conversando con nosotros. El efecto es la paradoja de una escritura oral, una escritura que nos apura a través de la inmediatez con que nos apela. JEB escribe lo que afirma, pero lo leemos como si lo oyéramos. Nos comunica datos, hechos, sucesos objetivos, pero involucrándonos en sus contextos bajo el modo pasional de una intersubjetividad que nos sabía ya involucrados con él y con los hechos, desde hacía ya largo tiempo. JEB menos escribe que nos escribe, nos interpela en nuestros gustos y disgustos como si nos conociera. Su actitud interrogativa sobre lo que escribe, incluyéndose a sí misma, invita a interpretar, a singularizar lo que leemos como partes de un puzle; discontinuo con respecto a cualquier idea de completitud. ¿Dice este puzle todo lo que muestra y sugiere su escritura? No, JEB escribe dejando qué desear al lector. Deja que desear tanto por las situaciones fugitivas que menta sin definir, como por los géneros literarios de que se sirve (dramático cuando nos urge, poético cuando nos ensueña, épico cuando nos impulsa a vivir un presente sin tiempo), pero sin anclarse a ninguno. En este sentido su escritura es camaleónica — como Alfonso Reyes definió al ensayo. Al remedar

\footnotetext{
${ }^{8}$ Me refiero a las 3006 páginas que suman los cuatro volúmenes de Crónicas reunidas, de Joaquín Edwards Bello, reeditadas bajo el cuidado de Roberto Merino y publicadas por la Editorial Universidad Diego Portales entre los años 2008 y 2012. Estas crónicas fueron publicadas originalmente por JEB en los diarios La Nación, El Diario Ilustrado y el vespertino Los Tiempos entre 1921-1935. El volumen I (2008), editado y prologado por R. Merino, agrupa las crónicas publicadas entre 1921-1925. El volumen II (2009), editado por R. Merino con prólogo de Héctor Soto, agrupa las crónicas publicadas entre 1926-1930. El volumen III (2011), editado por R. Merino con prólogo de Manuel Vicuña, agrupa las crónicas publicadas entre 1931-1933. El volumen IV (2012), editado por R. Merino con prólogo de Cecilia García-Huidobro, agrupa las crónicas publicadas entre 1934-1935. Citaré cada volumen por su número romano y página.
} 
Dossier. Roberto Hozven. "Patrimonialismo y casuismo, puerto y 'santiaguinería', en las crónicas ensayísticas de Joaquín Edwards Bello".

todos los géneros, sin fijarse en ninguno, sus crónicas devienen la expresión más vívida de un exceso que testimonia la radical incompletitud de su escritura con respecto a lo real que aspira a representar. Esta incompletitud viene de cualquier parte, sea de sus referentes (la heteroclicidad de la sociedad chilena que pulveriza taxonomías simplistas) como de la diversidad de asociaciones que despierta el "vasto Cosmos donde nos encontramos"9.

Esta incompletitud abre su escritura al segundo rasgo fundamental del ensayo: la intrusión de una tercera voz que se filtra entre el yo que escribe, el mí que rumia lo escrito -insistente en JEB - y la objetividad descrita ${ }^{10}$. Esta voz — ni del yo escribiente ni del objeto - testimonia la radical discontinuidad de lo real, explora lo errático de la vida cotidiana tentada por la "infinitud de fuerzas siderales, metidas como por castigo dentro [del limitado marco del discurso] de [los] cinco sentidos” (JEB). Esta voz intrusa no corresponde a personajes sino a formas enunciativas (que muestran posiciones subjetivas desde las que se habla), a actitudes discursivas (que informan el modo en que el sujeto escribiente se relaciona con sus contenidos) y a figuras textuales ${ }^{11}$ que consignan identidades nacionales o político-ideológicas. Estos procedimientos semióticos introducen un desajuste entre el lugar que habitualmente ocupamos o creemos ocupar con el discurso - lugar fundado por una creencia legitimada desde siempre - y el lugar e intereses desde los que ese discurso efectivamente enuncia los procesos de producción que lo originan. Si escuchamos que "Las masas lo esperan todo del gobierno" es porque esta afirmación coincide con la creencia patrimonial ${ }^{12}$ el lugar fundado- de que "casi siempre entendemos al gobierno como la expresión o adorno de las actividades del edificio social" (IV 302). En este momento, sobreviene una voz ensayística cuestionadora cuya actitud crítica sugiere que nos parecemos a:

\footnotetext{
9 "Sí; yo creo firmemente que el hombre es algo astral; es una infinidad de fuerzas siderales, metidas como por castigo dentro de cinco sentidos solamente, para que el vasto Cosmos, donde nos encontramos, sea un eterno misterio. Yo he creído siempre a mi manera. La rebeldía ha de ser completa" (II 656).

${ }^{10}$ Estos dos rasgos del ensayo los tomo de Roland Barthes, Roland Barthes par lui-même. 123-124.

11 "Formas culturales que pueden tratarse como textos, obras de imaginación construidas con materiales sociales. A la vez reflejos de sensibilidades preexistentes representadas analógicamente, y agentes dinámicos en la creación y conservación de esa sensibilidad" (Sylvia Molloy $16 \mathrm{n} .5$ cita a Clifford Geertz 449-451).

${ }^{12}$ Arraigada en "toda la estructura social del Estado hispanoamericano" por su génesis histórica: "[E]l Rey [español], centro del orden legítimo, es un señor en posesión de su territorio". Su poder sobre el Nuevo Mundo, por bula papal de 1493, es sagrado, paternal y absoluto. Este concepto "permeó el sistema prebendario de la administración pública: 'recompensa servicios prestados', 'vende oficios públicos', "corolarios lógicos del concepto de patrimonio del rey" (Mario Góngora $82 \mathrm{ss}$ ).
} 
un pueblo de niños caprichosos que no saben lo que quieren ni se deciden a tomar camino alguno. ¿Remedio? Jamás podrá salir su remedio de la política [es decir, del gobierno-adorno] sino de la escuela, del libro, del educador, del espíritu religioso independiente, de la prensa en general (29/ 11/ 1934, IV 302).

Esta voz ensayística recesiva y discrepante que se filtra por la actitud subjetiva acuñada por la enunciación, infaltable en las crónicas de JEB, es la que realiza la "crítica [de] la vida cotidiana chilena mostrando una lúcida conciencia del tiempo de lo cotidiano moderno" (Morales 58-59). Esta crítica repudia, en el Chile de 1934, la presencia de modelos culturales, políticos e ideológicos premodernos, autoritarios, anacrónicos por su factura patrimonial, en el incipiente Chile moderno de la primera mitad del siglo XX: "Todo ha sido tribus, componendas, partidos; al que pertenece al partido adverso, no se le reconoce nada; se hacen barricadas doctrinarias hasta para los negocios y aun en las prácticas corrientes de la vida social" (IV 303). Frente a este anacronismo del carácter santiaguino Santiago como epítome y símbolo del conservadurismo retardatario de todo Chile es frecuente en las crónicas de JEB_-, está la celebración contrastante del buen ejemplo anglo-sajón, liberal-mercantilista de:

el 'carácter porteño', el que se diferenció notablemente del carácter santiaguino y cuya influencia fue favorable en el desarrollo y salud de la República". "Valparaíso escuela de espíritu cívico, de puntualidad, de franqueza, agilidad corporal y espíritu de trabajo". "El baño, el telégrafo, los tranvías, el diario, la liberalidad en los temperamentos entraron por Valparaíso (IV 322). Médium de Europa (II 357).

Sin embargo, este elogio del civismo y espíritu emprendedor del criollo porteño a la inglesa, en su asimilación del liberalismo mercantilista inglés, se matiza por la crítica de JEB al mimetismo blanqueador de "los malos ricos que no aman a Santiago, ni a los chilenos, sino a París y a los europeos" (II 168). Es el:

chileno rico que paga sin refunfuñar a una nurse para que su hijo olvide el español (suprema elegancia) pondrá el grito en el cielo si la china nacional pide diez pesos de aumento. Quieren la eterna sierva zaparrastrosa de siempre. Pero el maître d'hotel del Palace de Deauville, o al ayuda de cámara del Ritz, les darán lo que pidan por sus reverencias. (ibid.) 
Dossier. Roberto Hozven. "Patrimonialismo y casuismo, puerto y 'santiaguinería', en las crónicas ensayísticas de Joaquín Edwards Bello".

El rastacuerismo es rechazado, primero, por su remedo patético de prácticas sociales ajenas, foráneas y trasplantadas: "tiene más interés La dame de chez maxims que Don Segundo Sombra"13. Enseguida por su carácter "denigrador de todo lo nuestro" (II 169): el rastacuero prolonga en París, Londres o Madrid el hábito colonial de cambiar "la roña de Europa" por el capital nacional recibido en su calidad de "rentista internacional" (ibid.). Finalmente, el rechazo asume carácter autocrítico: "declaro que siento por ellos instintiva antipatía, que tal vez será debilidad o hasta envidia. No sé. Acaso es el estremecimiento del ratón ante los encandilados ojos del gato. Ellos son los fuertes” (ibid.) La voz cronística, como otros lúcidos ensayos de nuestra actualidad chilena ${ }^{14}$, muestra que "el proceso de formación y gestión de la nueva burguesía" incluye alternativamente, en el seno de un mismo proceso asimilador, un movimiento centrípeto ("espíritu cívico de puntualidad... y trabajo") con otro centrífugo (de dispendio neocolonial: "cambiar la roña por el capital rentista”) que incluye, finalmente, una autoconciencia de la envidia y vértigo íntimo de la conciencia del sujeto moderno en su "tránsito de la ciudad patricia en ciudad burguesa" (Morales 64). En este “proceso de tránsito (o de recomposición) de las formas del poder (político, económico, cultural) desde un paradigma colonial [patricio] a un paradigma moderno [burgués]" — asunto preferente de las crónicas de JEB-, Morales anota dos observaciones importantes para este estudio. Primero, la "recomposición de las formas del poder del paradigma colonial a un paradigma moderno", no significa (yo subrayo):

“la desaparición de constantes 'estructurales' asociadas a los orígenes y a la historia del poder en Chile (a las que más adelante me referiré con el nombre ya acuñado en Chile desde Portales, y que Joaquín Edwards evoca: el 'peso de la noche')" (Morales 64).

¿Cuáles son estas "constantes estructurales" coloniales, supérstites en la modernidad periférica chilena de la primera mitad del siglo $\mathrm{XX}$, e ineluctablemente asociadas a los orígenes e historia del poder en Chile que Morales refiere como "peso de la noche"? A mi entender, puesto que Morales no las específica, son el patrimonialismo y el casuismo que “el surgiente Estado renacentista de la corona española pudo crear [en Indias] como una

\footnotetext{
${ }^{13}$ La gran novela criollista de Ricardo Guiraldes (1926) escrita en discurso modernista dariano y simbolista francés.

${ }^{14}$ Pienso en el Diario íntimo de Luis Oyarzún (1995) y en el Diario de recuerdos y de cosas vividas (2017) de Raúl Ruiz.
} 
estructura política centralizada sin el obstáculo de tradiciones feudales ni la oposición de la aristocracia periférica [como sí ocurrió en las amuralladas ciudades europeas dentro de sus recintos feudales]" (Véliz 21) ${ }^{15}$. El propósito mayor de las crónicas de JEB es hacer la crítica de la subsistencia y autoritarismo político-social y cultural de estas dos instituciones, a la vez medievales e inauguralmente modernas, en la sociabilidad burguesa aspiracional del santiaguino y del porteño.

Volvamos a la instauración del patrimonialismo y el casuismo por la corona española al alba de la Colonia. La corona las establece en América hispana por un "tipo de política civil centralista ${ }^{16}$, burocrática y legalista" (Véliz 22), arraigada en su "común tronco ibérico" (26) y que operará como "disposición secular en la sociedad latinoamericana" (15). El rey de España asume el papel de "señor absoluto que no conoce superior ni freno" (José V. Lastarria 25), jurídicamente "propietario único de las Indias" testimoniado por el lema regalista “Un Dios, una Fe, un Imperio" (Stoetzer 33). Fue el régimen político-jurídico de la Colonia hispanoamericana. Las independencias no cambiaron esta anterioridad burocrática, la continuaron en cuanto "en América Latina la creación de la burocracia urbana precedió la construcción de las ciudades” (Véliz 226):

Los burócratas resultaron indispensables... una burocracia experimentada y permanente era esencial si es que aquellas remotas provincias [los países hispanoamericanos] iban a retener siquiera un vestigio de administración... a través de su experiencia ejercieron su poder omnipresente sobreviviendo innumerables despotismos, reformas, revueltas palaciegas, conspiraciones e intrigas políticas, hasta que gradual e inconscientemente fueron inculcando a sus respectivas sociedades las disposiciones centralistas [patrimonialistas] que sabían manejar y para las que no se había encontrado ningún sustituto adecuado durante aquel ajetreado siglo. En el mismo centro de la escena nacional, aunque ocultos por su anonimato burocrático, persistían porque eran necesarios, y también por ser políticamente ambivalentes y técnicamente irremplazables" (Véliz 149).

\footnotetext{
${ }^{15}$ Agradezco a Alejandro Valenzuela, miembro del seminario de investigación FONDECYT 1160230, por su contribución a FONDECYT y a este estudio con las citas "centralistas" y "burocráticas" provenientes del libro de Claudio Véliz.

16 "Centralismo", en Véliz, corresponde al "patrimonialismo estamental" de Weber (184-185): "[E]1 Rey [español en Hispanoamérica], centro del orden legítimo, es un señor en posesión de su territorio" (supra n. 12). "Centralismo" - creo - abrevia la frase weberiana en la medida que implica el estamento burocrático en Hispanoamérica.
} 
Dossier. Roberto Hozven. "Patrimonialismo y casuismo, puerto y 'santiaguinería', en las crónicas ensayísticas de Joaquín Edwards Bello".

Desde la independencia acá, estos burócratas integraron los cuadros de la gobernanza jurídico-política, económica y cultural de la elite republicana — sucesivamente pelucona, pipiola, liberal y hoy día neoliberal - e hicieron posible su administración. Lo hicieron sobreviviendo “despotismos, reformas e intrigas políticas” gracias a su experiencia de saber qué y cómo hacer en el manejo de "las disposiciones centralistas de sus respectivas sociedades". Sobrevivieron manipulando los protocolos que regían, rigen, el "cuadro formal y uniforme, universal, de conductas morales autorizadas" por el edificio del Estado (Cariou 210). Supieron uniformar conductas, contener desviaciones y racionalizar "políticas ambivalentes" — aunque "técnicamente irremplazables" — adoptando el rol de intermediarios entre casos anómalos y la corrección exigida por las instituciones, para cumplir así sus objetivos de uniformización de las conciencias. En suma, no estamos hablando tanto de patrimonialismo como de su legitimación discursiva, la gestión por la que se obtiene de "una parte relevante de la población un grado de consenso tal que asegure su obediencia" (Bobbio 862). La obtención de este consenso, desde la Colonia a hoy en día la burocracia lo hizo de modo casuista. Casuista por los dos modos de proceder de la vocación burocrática: primero, “infiltrándose en las conductas particulares [del súbdito ${ }^{17}$ ] con el fin de hacerlas compatibles con las prescripciones ideales de las reglas" exigidas por la institución (Cariou 211). Esta infiltración psíquica casuista procede por "obra de verbalización unilateral". Unilateral en la medida que la convicción verbal o escrita, conquistada por el casuista sobre su interlocutor $-\mathrm{y}$ este es su segundo modo-, "prescinde de los efectos que esta convicción produzca en la realidad existencial de los sujetos sobre quienes se ejerció" (ibid). Lo que importa es la estructuración de una regla, no la preocupación por una realidad subjetiva; la subjetividad del sujeto es omitida en aras de la permanencia de la institución. El asunto es obtener la obediencia del interlocutor, o el consenso de la población, gracias a la limpidez, precisión y "belleza árida” de la fórmula

\footnotetext{
17 Digo "súbdito, no ciudadano, porque la existencia del sujeto se omite bajo la norma, se omite su singularidad existencial. Procedimiento inverso al que regirá las relaciones sociales a partir de la Ilustración: la "Ley de la Opinión Pública". Ley que viene después de la Ley de la Deidad ("ley divina que mide el pecado y el deber") y de la Ley Civil ("la ley del Estado armada con la coacción legal"). A través de la Ley de la Opinión Pública, la ética burguesa, esencialmente tácita y secreta, se mueve hacia el dominio público, apareciendo como un estado de la mente humana capaz de determinar el valor moral de las acciones humanas. La razón necesita del perpetuo proceso de la crítica para establecerse como autoridad moral suprema, como ley vinculante que le permita al ciudadano elevarse al Estado mediante el ejercicio de su ciudadanía. Así la acción pública se funda no solo por la autoridad del Estado, sino porque este resulta de la autoridad moral concedida por la ciudadanía (Reinhart Koselleck 55-58).
} 
asestada por el casuista, con prescindencia de los sujetos a quienes se aplicó. De este modo, el burócrata-casuista consigue su doble proyecto de fondo: uniformar conciencias dictando fórmulas de conducta que la otredad debe cumplir, conforme a ortodoxias acuñadas de modo soberano y de las que el casuista es humilde servidor a la vez que revelación encarnada (ibid). Richard Morse, en sus dos grandes estudios sobre la sociabilidad latinoamericana, muestra que "su doctrina amoldable" está pensada para "incorporar diversos códigos morales de modo asimétrico" (la elite no es punible del mismo modo que lo será el pueblo llano). Así se "armonizan” la variedad de doctrinas e instituciones que componen el edificio social (1989 197). El casuismo hizo de la raison d'État (implementación de la política sin consideraciones morales) una suerte de estrategia acomodaticia que, "permeando toda la sociedad", permitió "al inconsciente individual y colectivo servirse de tácticas acrobáticas para enfrentar situaciones imprevistas” (1982 85). Fue el modo de operar de la burocracia desde la Colonia a hoy en día (Góngora 94-108).

La segunda observación de Morales que retengo es que las "constantes estructurales" 18 de la burguesía chilena, en su pasaje desde el paradigma colonial al de la modernidad liberal, JEB las evidencia y critica en su discurso cronístico mediante "códigos de lectura 'deconstructores' del tramado ideológico de los signos” (Morales 69). Ahora bien, ¿cuáles serían algunos de estos “códigos de lectura” deconstructores del entramado de los signos? Sirviéndose de una categoría de Michel de Certeau, para estudiar las maneras de operar y de hacer de las personas en relación con su medio social, según sea el grado de fuerza y de efectividad con que intervienen el campo en que se desempeñan ${ }^{19}$, Morales identifica y ordena el discurso cronístico de JEB en dos grandes grupos: el de las "crónicastácticas" y el de las “crónicas-estrategias". En las primeras, sus agentes son "usuarios" porque actúan en un campo social "prestado", sin prehistoria conocida que les permita proceder con "conocimiento de causa" del campo en que se desempeñan. Sus acciones ocurren en el campo del otro y dependen de las acciones de esos otros. Por ende, se definen por relaciones de adversidad, competencia, clientelismo o, en general, subordinación a los

\footnotetext{
18 "Constantes estructurales", es decir, la doble institucionalidad patrimonialista ("centralista" para Véliz) y casuista.

${ }^{19}$ Las personas se sirven de "estrategias" cuando tienen el poder de "aislar" el medio en que operan, y así controlan a voluntad el campo social donde se desempeñan. Las personas acuden a "tácticas" cuando no tienen poder ni control sobre el medio en que interactúan, dependen del cálculo de los actos sociales hechos por otros (de Certeau xix).
} 
Dossier. Roberto Hozven. "Patrimonialismo y casuismo, puerto y ‘santiaguinería’, en las crónicas ensayísticas de Joaquín Edwards Bello".

agentes del segundo grupo. En las “crónicas-estratégicas”, sus agentes son "propietarios” porque controlan el espacio social y cultural en que se desempeñan. Por ende, deslindan su campo de acción y de enunciación e, incluso, podrían "aislarlo" de otros campos sociales concurrentes. Disponen de un poder rector programador (Morales 72-73). Morales privilegia estas crónicas estratégicas porque su "crítica de la vida cotidiana chilena se vuelve más radical... son las que tocan fondo" al "entrar allí donde el otro, el poder que condiciona las relaciones de la vida cotidiana, se enmascara, se oculta tras sus mediaciones, y de la manera más eficaz tras sus "naturalizaciones"” (73).

Hoy en día, treinta años después del libro de de Certeau sabemos que no solo el "lugar de la táctica pertenece al otro" (xix), sino que todo discurso —incluso el de "nadie a todos" circuito en que el sujeto se integra consciente-inconscientemente y que, por ende, está condenado a repetir quiéralo o no" 21 . Por ende, cada vez que hablamos o escribimos (no literariamente $^{22}$ ) es merced, primero, a la existencia de relaciones discursivas fundamentales que ya están en el mundo y, enseguida, por el ingreso sistémico de la estructura del sujeto en lo social, con y en lo que a ella corresponda. En suma, hablamos desde la identidad entre una articulación subjetiva y la estructura que la constituye como sujeción social (Chemama 2001 251). Esto es así porque el inconsciente es, primero que nada, social y:

'trans-individual'. Existe más allá de la oposición ideológica entre inconsciente 'individual' y 'colectivo'. El inconsciente del sujeto está siempre fundado en una relación transferencial con el Otro; es siempre externo con respecto a la existencia monádica del sujeto. (Žižek 40, n. 36).

\footnotetext{
${ }^{20}$ Así traduzco "à la cantonade": discurso que habla a ningún interlocutor preciso e, incluso, sin esperar respuesta.

21 "Este discurso del otro... es el discurso del circuito en el que estoy integrado. Soy uno de sus eslabones. Es el discurso de mi padre... en cuanto mi padre ha incurrido en faltas que estoy absolutamente condenado a reproducir. Retomaré el discurso que él me ha legado, no porque sea su hijo, sino porque no se detiene la cadena discursiva, y que yo estoy justamente encargado de transmitirlo en su forma aberrante a algún otro" [Yo traduzco]. Jacques Lacan 112.

${ }^{22}$ Porque la escritura literaria "es esta actividad que trabaja las imposibilidades de la lengua en provecho del discurso [inédito]". R. Barthes, "Longtemps..." (462). La buena literatura, al extrañar sus codificaciones y presuposiciones ya conocidas, nombra al mundo de un modo original. El discurso cotidiano, en cambio, repite lo semejante, lo ya sabido.
} 
Por ende, no hay "estrategia" aislada de su medio y, mucho menos, un Poder propietario de su discurso o de su propio campo discursivo. Razón por la que privilegiaremos —en los análisis de las crónicas de JEB que siguen - todas las tácticas, formas, figuras enunciativas y procedimientos deconstructivos por los que el discurso cronístico de JEB tanto reproduce las sujeciones sociales negativas de su comunidad chilena de origen (la porteña y santiaguina en sus configuraciones patrimonialistas y casuistas) como las impugna y reprende sirviéndose de las voces recesivas e intrusivas propias del ensayo. En suma, no existen sujetos "propietarios" del campo de enunciación y de acción del lugar social y cultural en que se sitúan y desempeñan.

\section{Porteños y santiaguinos en el discurso cronístico-ensayístico de JEB}

El 6/ 7/ 1922, JEB escribe "Yo soy el literato de Valparaíso, me precio en serlo. Ahí nací, de allá soy. Por eso mi prosa es como ese viento del verano 'que corta como hacha de abordaje', que lleva una arenilla que se mete en los ojos, en los zapatos y hasta en la sopa.” (I 503). Juicio que reitera siete años más tarde, el 21/ 3/ 1929, al regresar de Londres: "Yo, viejo porteño, hijo pródigo, he regresado a Valparaíso y a los pocos días me he sentido henchido de un saludable renuevo; me he sentido poseso de una energía rara y como vislumbrada en sueños" (II 708).

JEB se siente y se construye a sí mismo — con plena convicción moderna- como un efecto de su prosa en la medida que ésta procesa: primero, las circunstancias donde nació: Valparaíso “capital del mundo" (IV 504), lugar de privilegio del "vasto Cosmos donde nos encontramos", dotado "de una energía rara y como vislumbrada en sueños" y; enseguida: desmitifica las instituciones (patrimonialista, casuista) de su aspecto consagrado por el contra-uso que hace de lo que en ellas desprecia: meter como por castigo la infinidad de fuerzas siderales solo dentro de cinco sentidos (II 656). La cura es complicarlo todo, es decir, explorar correlaciones heterológicas ${ }^{23}$ entre la infinidad de fuerzas y elementos que hacen de Valparaíso, y de él mismo, no ya cinco sentidos sino una travesía de los sentidos.

\footnotetext{
23 "Cuando una actividad discursiva es una forma de actividad social, de modo tal que a esta le aplicamos la enunciación asumida con la primera" (Godzich xxi). La inexistencia de clases medias en el puerto —afirma JEB - es concomitante a su diáspora urbano-discursiva. Según Barthes, se trata del "frotamiento de lenguajes diferentes" ("Bernard" V 471).
} 
Dossier. Roberto Hozven. "Patrimonialismo y casuismo, puerto y 'santiaguinería’, en las crónicas ensayísticas de Joaquín Edwards Bello".

¿De dónde esta "rara energía” porteña, y por qué es "vislumbrada en sueños”? Es la energía rara de "las angulosidades y extravíos de dibujo cubista" (I 487), que hacen de Valparaíso una ciudad icónicamente hermana del París surrealista de artistas y escritores, signado por "el puntero de la torre Eiffel" (I 450) del caligrama huidobriano. Testimonio geológico, hoy, todavía, del poder genésico de "cataclismo volcánico" (I 487) que sostiene su "espíritu disperso y nómade" (I 475). Su "anfiteatro del puerto" (I 481) hace de Valparaíso un "caleidoscopio de los recuerdos" (ibid), una ciudad "médium de Europa" (II 357), superior a "cualquiera playa de la Riviera: Niza, Cannes" y equivalente a "Córcega, nido del águila imperial... en sus crestas quebraduras y cortes a pico" (I 487). Valparaíso ciudad médium por su espíritu, caleidoscópica por sus quebraduras y cortes a pico, literaria por su caligrama Eiffel, artística por sus extravíos cubistas es un "miembro fantasma", en Chile, de soberbias ciudades del mundo (París, Londres, Madrid) y evocadora geográfica de la génesis del imperio napoleónico. Estos "miembros fantasmas" se reencuentran como “cuerpo repartido" (Ruiz II 506) en el escenario heteróclito de sus cerros y quebradas. Valparaíso, como cuerpo repartido de miembros fantasmas dispersos por el planeta, es una imagen fantástica ${ }^{24}$ de un procedimiento de evocación histórica extensivo a todas sus crónicas: revivir el mundo con los ojos del primer día, el cuerpo bajo los toques del primer encuentro:

con la atmósfera que hemos respirado, con los hombres a quiénes habríamos podido hablar ... Dicho de otro modo, la imagen de la dicha es inseparable de la redención. Así ocurre con la imagen del pasado de que se ocupa... el historiador, el cronista materialista consciente. (Benjamin 428).

Las menudas representaciones de la vida cotidiana porteña, de que estuvo hecha la atmósfera del primer día del cronista JEB, se espejean con las experiencias posteriores, cosmopolitas, del viajero JEB. Las segundas, por la intrusión y recesión ensayísticas operantes en el interior de sus crónicas, revelan en el pasado del recuerdo fantaseado mientras leo- las enunciaciones y situaciones patrimonialistas y casuistas inseparables de su historia vivida. Estas revelaciones negativas, incluso supérstites en el instante de lo que está siendo para lo que escribe, asumen un carácter epifánico por el cambio futuro que la

\footnotetext{
24 “Insisto: el papel principal de la crónica es la descripción/ invención/ lectura fantástica o naturalista de la Ciudad, que ha de remplazar a la Naturaleza" (Carlos Monsiváis 47).
} 
Nueva Revista del Pacífico 2020, № 72, (214-238). ISSN (e) 0719-5176

conciencia recesiva del ensayo le va imprimiendo a su crónica. De aquí, creo, el estilo espumante, entusiasta y positivo de sus crónicas. Los sentidos evocados, por negativos que sean, nunca cristalizan en verdades obturadoras de lo que sus crónicas nos revelan en el ahora de su lectura. Quiero decir: JEB no hipostasia los sentidos revividos en verdades consagradas; los sentidos encarnan en verdades espumantes, provisorias y cambiantes.

Revisemos algunos recuerdos fantaseados. Evocando la cordillera santiaguina, JEB escribe:

en las tardes de verano la cordillera arrebolada es como un animal vivo y desollado que miraba con ojos espantados el matadero eterno de la naturaleza... La cordillera es el desperdicio de gigantes conmociones, de maremotos y sacudimientos formidables. Recostada en América es un esqueleto: la carroña del dinosaurio geológico, esa catedral vacía y ruinosa de la especie animal. En cambio, las colinas de Quilpué son plenas como parroquias pastorales (II 675).

JEB no describe la cordillera que enmarca Santiago, la siente en su génesis arcaica. Su espanto es doble: el testimonial de su génesis geológica, como si hubiera asistido a su parto petrificado en el tercer día de la creación; y otro sociológico, en el que la cordillera es telón alegórico de la génesis social patrimonialista y casuista, negativa, de Santiago. Ante la cordillera, JEB es médium, voz y cuerpo transferencial a través de quien las conmociones sociológicas que sacuden a la sociedad chilena (equivalentes a otros tantos maremotos y sacudimientos urbanos formidables) comunican figuras que él solo parece intuir y ver. Estos sacudimientos formidables ocurren sintomáticamente en Santiago, síntesis de Chile, y repercutirán luego en Valparaíso. De modo atenuado primero — por la "fuerza astral" que lo inspira y protege (II 656) — y catastróficamente enseguida: terremoto de 1906, apertura del Canal de Panamá en 1914 y el crecimiento concurrente del Puerto de San Antonio, a partir de las décadas 1910-1920.

¿Cuáles son los espantos sociológicos que muerden como una serpiente la sensibilidad de JEB? ¿Cuándo su voz recesiva cae en ineludible relación transferencial, sin razón aparente y con la gratuidad de la transferencia? Todas las veces que el espectáculo cordillerano se torna "carroña de dinosaurio geológico", y lo desuella como cosa viva provocándole un cortocircuito existencial. Cada vez que observa y anota sucesos tales como: 
Dossier. Roberto Hozven. "Patrimonialismo y casuismo, puerto y 'santiaguinería', en las crónicas ensayísticas de Joaquín Edwards Bello".

Ocurre en los países de contextura colonial que se forman dos castas pese a la cacareada homogeneidad de la raza - y la casta superior quiere llevárselo todo. Le parece lo más natural darse sueldos enormes, reservando al pueblo -"que no necesita como ellos"- salarios de hambre (IV 527).

Santiago nació a la vida con un temperamento campesino y conventual; era una aglomeración de conventos con huertas y enormes claustros: cada calle lleva aún el nombre de un convento: Agustinas, Compañía, Claras, San Francisco..." (I 475).

Horror a la santiaguinería hay en todos los puertos donde se trabaja, en los centros mineros del norte y los agrícolas del sur hasta Magallanes. En Santiago se habla y se vocifera [...] En el parlamento se otorgan pensiones, jubilaciones, adelantos, con el más espléndido gesto de príncipes rusos en el banquete, o chuña, como un valiente diputado calificó hace pocos días estos repartos (IV 317).

[L]a democracia en estos casos no es tal democracia, sino vicio, por cuanto esos "demócratas" pretenden serlo solamente para vivir como grandes duques ( $I V$ 507).

Lo que no existe en Santiago [sí en Valparaíso] sería un cerro poblado cubierto de casas, urbanizado como los de Valparaíso (IV 514).

[En cambio sí existen] los túmulos funerarios y horrendos monumentos de la Alameda; la corta de árboles frondosos (IV 521).

El Hospital San José... demasiado realista. A cada instante se ven pasar los muertos; unos al depósito, otros a la tumba. La muchacha que vino de provincias, a esta Meca chilena, llena de esperanzas; el obrero nortino, desocupado; el joven que la semi-alimentación destruyó desde la cuna... El Club de los suicidas (IV 518).

Hace ya algún tiempo noto en mucha gente el deseo de morir... En pocas horas de distancia se suicidaron, arrojándose al tren un hombre y una muchacha. Anda por el pueblo como una racha de incertidumbre y cansancio (IV 526).

Se siente en Santiago, particularmente, un largo grito de puerperio, un llamado vaginal anunciador de pimpantes novedades. [Ante] una Sociedad de Demoliciones... cuando recordamos la destrucción del puente del corregidor Zañartu (IV 479).

Esta imaginería a ras de suelo hace de la cordillera la medida invertida del estrago social santiaguinero (el habitante de Santiago no merece más de este menosprecio derivado): convierte las cimas cordilleranas en simas sociales, cavidades profundas de desigualdad e injusticia ciudadanas. La cordillera es fuente y figura alegórica, imaginaria, de la sociabilidad chilena en sus distintos estratos institucionales. El valle de Santiago es el resumidero donde se concentran las carencias y horrores de la gobernanza administrativa: patrimonialismo, por su modo de posesión del suelo y dominio del Estado; casuismo, por 
los modos de acomodación cívicos de la santiaguinería clientelista. Réplica del orden colonial de castas (la abusiva/ la abusada) y sus componendas clientelistas (su chuña repartidora de puestos, su democracia nobiliaria). La omisión de la inversión pública en salud popular — problema de hoy en día - y la imprevisión ante el desempleo de los jóvenes —origen de ruptura generacional - es acuñada por la imagen cordillerana de "matadero eterno de la naturaleza". Su urbanismo auto-destructor si no auto-saboteador. El "odio al árbol” —observación luego ampliada por Luis Oyarzún 25.

El matadero conforma una escena-fantasma ${ }^{26}$ : en ella JEB — su intrusa y recesiva voz ensayística - ve “con ojos espantados” a la joven provinciana, al obrero cesante, al joven desnutrido, como otros tantos alter egos, compañeros de infortunio, de una escena fantasmática que los incluye. El fantasma ignora las castas ("superior/ inferior") y torna la oposición ("sueldos enormes/ salarios de hambre") en una identidad, en cuanto el fantasma inconsciente, como el sueño, "no conoce la oposición. Lisa y llanamente la omite" 27. Luego, en este fantasma cordillerano, JEB se figura, se concibe a sí mismo como un "animal vivo y desollado" que es a la vez joven desencantada, obrero cesante y joven desnutrido-destruido desde la cuna. Además —continúa Freud, profundizando su afirmación anterior-, la lógica onírica "en una parte de los casos" "figura lo inverso, lo contrario" de "una manera asombrosa y casi se diría chistosa" (op.cit. 331). Trastrueca el "arriba" y el "abajo" — homólogos a la distribución de la riqueza en castas de factura colonial - por la substitución del uno por el otro. Este trastrueque onírico incrementa el desuello de JEB: "el matadero eterno de la naturaleza" lo incluye con sus compañeros de infortunio. Concentra en su sola figura enunciativa el desencanto, el desempleo y la desnutrición incrementando la tensión psíquica. Este incremento de tensión psíquica, en las crónicas de JEB, no solo abre un registro trágico, revelador de catástrofes geológicas y sociales, sino también otro cómico, que da lugar a paradojas u oxímoros grotescos. Por ejemplo: el "alumbramiento destructor". En Santiago — cité antes_-, aún en períodos de

\footnotetext{
${ }^{25}$ Diario íntimo, entrada 17/ 02/ 1959, p. 308. Luego, en su vehemente opúsculo Defensa de la tierra (1973), a un mismo tiempo, Oyarzún se pasma ante la belleza de la flora chilena, se conduele por los árboles ("gloria de la Creación") "arrasados por simple avidez de lucro", por los "desiertos forjados por el hombre en todos los continentes”, y se pregunta por la pulsión de muerte con que el hombre, arrasando al árbol, se suicida ecológicamente sobre el planeta.

${ }^{26}$ Fantasma: escena imaginada en la que el sujeto se ve y participa. "Guion escénico imaginario, consciente (ensoñación), preconsciente o inconsciente, que implica a uno o a varios personajes y que pone en escena de manera más o menos disfrazada un deseo". Patrick De Neuter, Diccionario del psicoanálisis. 248.

${ }^{27}$ Sigmund Freud. La interpretación de los sueños. OO.CC. IV, 32
} 
Dossier. Roberto Hozven. "Patrimonialismo y casuismo, puerto y 'santiaguinería', en las crónicas ensayísticas de Joaquín Edwards Bello".

espera ineludible ("puerperio") se siente el llamado pulsional ("vaginal") imperioso a destruir, con toda la plenitud ("pimpante") de que sea capaz un alumbramiento inminente. Por ejemplo, en 1888, el histórico puente de Cal y Canto, patrimonio colonial criollo, único en su especie en Chile y América hispana, fue dinamitado para ser substituido por dos ferrallas mecánicas de corta vida y peor estética. Hoy en día, este llamado pulsional destructor — creo — son las batallas rituales de los viernes libradas por las "primeras líneas" contra los "pacos", en la "plaza de la Dignidad” — ex-plaza Baquedano. Se lucha por la dignidad popular defraudada y violada por las más importantes instituciones estatales, públicas y privadas chilenas. Un oxímoron intruso y recesivo sería interrogarse —a la manera de JEB - si la dignidad violada se alumbra, castiga y restaura incendiando, saqueando, destruyendo los mismos monumentos y símbolos del Bien Común que la actualizan y operan: una plaza pública, un museo, un hospital, una iglesia, etc.

Si Santiago y el valle donde se enclava se encerraban en figuras cívicas de componenda autoritaria ("santiaguinería" clientelista) y de diseño urbano conventual (que proyectan su encierro a la nominación de las calles), Valparaíso es una herradura espacial de suerte prometeica. Faro que alumbra al mundo, puente de Santiago hacia las dos Américas (la hispana y la inglesa), tiene el arte y la inteligencia de abrir puertas y ventanas a los cuatro horizontes del espíritu. Valparaíso, siempre otro para sí mismo por su cuerpo repartido y poliglotismo — como el mismo JEB en sus lenguas española, francesa, inglesa y portuguesa-, habla, escucha y replica su pasión por los otros en las lenguas con que se entienden sus habitantes. Razón por la "que Valparaíso es un estanque o surtidor de gentes destinadas a brillar en otras regiones" (II 723); fuente de creatividad humana y renovación inventiva que "Chile mamó en el viejo old Valpo, y que viene a ser una mezcla de la flema anglosajona y del sueño cordial de Don Quijote de la Mancha” (II 724). Geológicamente, efecto de un cataclismo sideral, Valparaíso es "ciudad polvo de estrellas". Estamos ante una geología estelar performativa, no petrificada como la santiaguinera "carroña de dinosaurio geológico":

Valparaíso en semicírculo, parece un viejo anfiteatro incendiado... Arriba de cualquier cerro donde uno sube por placer el viento es más recio, barre el suelo, silba como culebra, y echa una granizada de arenillas imperceptibles que se mete por los ojos y que en la noche encontramos en los zapatos (I 487-488). 
[E]l cerro porteño produce una impresión aparte, una impresión especial que nada borra... Esos cerros están separados, partidos por profundos barrancos y quebra_duras; de todas partes se ve el mar como un vértigo. Los colores, las piedras, la vegetación, la tierra, todo es violento, insinúa la idea de cataclismo volcánico.

¿Qué panorama del mundo es parecido a ese... [A]glomeración de gente extraña a la tierra, gente triste y ambiciosa... calígine de razas y ambiciones. (I 487, 481).

El sudamericano de estos países de costa como Chile no está nunca bien seguro de qué raza y de qué contextura espiritual es. Yo nací en Valparaíso, donde las calles son un pandemónium de títulos escritos en todos los idiomas en medio del olor a tasajo... Cuando éramos chicos oíamos hablar un poco de toros, de zarzuela, de opereta francesa, de ópera italiana y de comercio inglés mayorista. Nos compraban ropa en la Casa Francesa, chocolates donde Swan y juguetes donde Burmeister. (III 142).

Valparaíso es una ciudad de contrastes violentos, de pobreza extrema o riqueza decisiva, y esto proviene de su propia configuración o morfología (II 716).

La geología "performó” a Valparaíso e hizo que sus habitantes la asumieran como ciudad "capital de mundo", "puerta [marítima] de nuestra América" (IV 504-505), abierta al tráfago de tradiciones que la conforman, a la aglomeración vacilante de identidades que ignoran sus progenies. Como si el viento desparramara la certidumbre de filiaciones étnicas y espirituales por los recovecos de su topografía, por sus calles que dan sobre el mar. Lo pueblan comunidades autóctonas e inmigrantes, inglesas, sobre todo. Las autóctonas, pueblo llano, por pobreza, se encaraman en los cerros distribuyéndose en sus barrancos y quebradas; los autóctonos ricos, inmigrantes incluidos, compran sitios en el plano distribuyéndose en dos grandes áreas: "la sociedad de El Almendral y el Barrio Puerto: la criolla y la gringa, o la jurídica-católica y la liberal-comercial" (IV 466). Sin embargo, todos estos habitantes, sea en el plano, en los cerros, o entre ambos entablan inéditas relaciones de proxemia $^{28}$ que JEB establece con acuidad avant la lettre. Por ejemplo: "Valparaíso es una ciudad de contrastes violentos, de pobreza extrema o de riqueza decisiva, y esto proviene de su propia configuración: lo rico y lo pobre sin la nota media es

\footnotetext{
${ }^{28}$ De proxemics: rama de la semiótica que trata del estudio y teorías sobre el uso del espacio humano considerado como producto cultural específico (E.T. Hall. The Hidden Dimensión, 1966). 'Dialéctica de la distancia' con que se estudia al espacio que rodea inmediatamente al sujeto (comenta R. Barthes en Comment vivre ensemble 155).
} 
Dossier. Roberto Hozven. "Patrimonialismo y casuismo, puerto y 'santiaguinería', en las crónicas ensayísticas de Joaquín Edwards Bello".

la vida misma de Valparaíso". JEB concluye "Desgraciadamente, el puerto no tuvo configuración para albergar una clase media reguladora, verdadera defensora social" (II 716, 717). Sabemos —después de Costa Lima, de Habermas o de Lechner, cf. Textos citados - las implicancias sociales, históricas y psicológicas de esta precoz observación heterológica sobre la sociedad porteña, de JEB, en 1929. Alcanza a toda América Latina: inexistencia de opinión pública, carencia de ley interiorizada, imposibilidad de neutralizar tendencias desintegrativas (cada individuo se arroga el derecho de abrirse camino por su propia fuerza y recursos), legitimación de políticas autoritarias (caudillismo), frondismo oligárquico (clientelismo de cuello y corbata), miedo como dimensión subjetiva de la política, etc.

En la conformación geológica de sus cerros, barrancos y quebraduras desde las que se ve el mar como un vértigo, los contrastes socio-económicos violentos, la emoción intelectual que suscita el viento astral ("fuerzas sideral metidas como por castigo dentro de cinco sentidos", "viento viajero, viento del mar, viento sur, principio vital, soplo espiritual" -II 690), el pandemónium callejero, la aglomeración de razas, de gentes, de tristezas y de ambiciones no se quedan en un mero decorado ornamental. Muy por el contrario, esta heterología de correlaciones que se frotan (lógicas de elite, de pueblo, diversidad y mescolanza de sus interacciones) configura modelos cognoscitivos que interiorizan actitudes y comportamientos híbridos en sus habitantes.

Consideremos estas dos citas:

"Valparaíso, como decimos nosotros los inglesados, tiene un ritmo más sano y más rápido que Santiago. Hay también más aire. Yo no sé en lo que consistirá, pero declaro que Valparaíso está más ventilado que Santiago" (II 82-83).

Recuerdo, en plena adolescencia, que me padre nos llevaba a la capital, y yo no podía entender, no podía comprender ciertas ceremonias de mandarines, muy gratas al espíritu santiaguino, y que provienen seguramente de la época colonial. Esos santiaguinos solemnes... me intimidaban ¡Qué abismo hubo siempre entre mi franqueza de la costa anglosajona y su recámara! (II 674)

Ambas citas establecen, primero, que Valparaíso (con su ventarrón libre) es a Santiago (encajonado en los contrafuertes cordilleranos) como la franqueza del puerto es a la recámara de la capital. Segundo, los santiaguinos solemnes intimidan, por sus placenteras 
ceremonias de recámara, al adolescente crecido en franqueza anglosajona. Aquí se impone un desvío por el uso riguroso de JEB de las sutilezas de la lengua ("encuentro de las dos palabras que encierran como cáscaras de nuez un alimento considerable" — II 470) para captar la plenitud de sentidos de las palabras puestas en juego. Una es "recámara" ("parte trasera del arma de fuego, lugar donde se coloca el cartucho", y "cuarto después de la habitación principal" — $D R A E$ ); la otra es la frase "ceremonias de mandarines", con los armónicos "gratas al espíritu santiaguino-colonial", intimidantes para un adolescente porteño. El sentido "sangrante" es ceremonia de pernada, violación de la criada de la casa que yace en el cuarto contiguo al principal ${ }^{29}$. Además, recámara —en su oposición a costa sajona-es modelo reducido del cívicamente amenazante, encerrado enclave cordillerano santiaguino; réplica geográfica de la Extremadura castellana de donde vino el conquistador español que legó, con el derecho de pernada, otras inicuas prácticas patrimonialistas denostadas por JEB. La relación proxémica que embarga a JEB en su relación con el paisaje (costa sajona/ cordillera extremeña) — entiendo - es que el aire (fluido astral de un puerto con dimensión de mar inmensos) imbuye de espíritu, de potencia de transformación, al sujeto porteño que lo inspira desde su nacimiento, en su suerte de herradura cósmica. Este aire impulsa al sobrevuelo imaginativo, huidobriano, hace hablar las escuchas que le imagina a su propia palabra, lo despega descentrándolo de la fuerza de gravedad cordillerana anclada en las costumbres institucionales intimidantes, reaccionarias y sacras de la colonia santiaguina. Si proxémicamente Valparaíso es vuelo, Santiago es encierro, entierro. Valparaíso "es la sede de la inquietud y la evolución. Dondequiera nuestra vista se dirija, recibe la impresión de novedad: mezcla de artefactos y estructuras alemanas, belgas, yanquis, inglesas" (I 152). Valparaíso es geológica y cívicamente moderno. Por el contrario, la santiaguinería se satura de iniquidad, hundido como lo está, bajo el peso de las atmósferas del mausoleo colonial, ruinoso y espantado de esqueletos triásicos y sociabilidades muertas que lo sepultan. Santiago es un convento "del españolismo donde hace furor lo colonial, lo antiguo" (I 512). Su tiempo social es desperdicio de franqueza y ocasión de gigantes conmociones.

\footnotetext{
${ }^{29}$ Tema de Juana Lucero. Los vicios de Chile (1902), novela de Augusto Thompson, recepcionada como escandalosa. Por "odio del escándalo" (explica JEB II 464), el autor cambia su nombre al pseudónimo Augusto D’Halmar.
} 
Dossier. Roberto Hozven. "Patrimonialismo y casuismo, puerto y ‘santiaguinería’, en las crónicas ensayísticas de Joaquín Edwards Bello".

Ahora bien ¿por qué este pegoteo inevitable de Valparaíso con Santiago, sea para valorarlo o criticarlo? ¿Por qué escribiendo sobre el uno no puede dejar de compararlo con el otro? ${ }^{30}$ Afirmándose como "el literato de Valparaíso" ("me precio en serlo. Ahí nací, de allá soy” -I 503), Santiago no deja de ser para JEB, ineludiblemente, el otro de su mí porteño. Su pasión por Valparaíso en su imaginación ascensional es maniquea: en un polo está el alumbramiento de esta "ciudad en formación constante" (II 299), donde la "infinidad de fuerza siderales" lo atraen hacia "el eterno misterio del vasto Cosmos en que nos encontramos" (supra n. 9). En el otro polo, está la prisión de los "cinco sentidos solamente", que lo arraigan a la fuerza de gravedad cordillerana que pesa sobre Santiago y su patrimonialismo capitalista familiar. Ambos polos, el astral y el pesadamente telúrico, "la parte inglesa que hay dentro de mí suele dar patadas a la parte hispana o criolla y viceversa. Esta es la base de mi literatura" (II 299). Ambas fuerzas conforman Chile, su escritura lo reproduce en su tensión antitética; raras veces dialéctica, en la medida que lo que predomina en sus crónicas no es la integración o superación de las contradicciones entre ambos polos chilenos, sino la mantención larvada de su tensión. La "vertical" cordillerana que retiene $^{31}$, anclada al furor del españolismo colonial de la santiaguinería, es materia heteróclita, plataforma introspectiva de donde irrumpe la rebeldía del hombre astral porteño. Ambos hombres, el astral porteño y el doppelgänger santiaguinero, no se entienden separados; la actitud intrusa y recesiva del primero sobre las reticencias y resistencias del segundo alimenta un diálogo polémico que mantiene en vilo las expectativas del lector. Este es el drama "base de su literatura".

Sabemos que ante la exclusión familiar de que fue objeto, en lo fundamental, JEB se excluyó de esa exclusión construyendo su propio camino. Lo hizo asumiendo en pleno su ejercicio de escritor moderno: "hacer historia con una condición: ver la cosa de otro lado y no decir lo mismo", procurar "colocarme como el chanchito de jardín que ve las hojas al revés" (II 76). Recurso heterológico, de frotación de lenguajes antitéticos, de quien "no quiere o no puede vivir como [su familia] quisiera: inventa, escribe” (IV 447). ¿Por qué? Porque es hablando y escribiendo como el hombre se produce. Y este producto, su escritura

\footnotetext{
30 Pregunta iluminadora de Lucía Guerra Cunningham... (RESTO DE LA CITA OMITIDA POR IDENTIFICACIÓN)

31 "Su vertical nos retiene" — escribe Gabriela Mistral en su poema “Cordillera” ( $1^{\mathrm{er}}$ verso, 7 ma sextilla, parte II).
} 
(“como el chanchito de jardín que ve las hojas al revés”) da cuenta de la sociabilidad chilena como un locus de interacción plural, incoherente y contradictorio de relaciones intersubjetivas (espíritu cívico y liberalidad/ temperamento campesino y conventual), urbanas (puerto astral/ cordillera... matadero telúrico), fantasmáticas (omisión y trueque de opuestos), ideológicas (modernidad/ colonialismo); todas atravesadas por "Los inventos derivados de la electricidad", efluvios "de esta vida moderna a base de barcos, linotipias, rotativas Underwood, electricidad, ferrocarriles" (II 471). Esta visión cronística de través, más que de revés, "relampaguea nuestro espíritu de una nueva manera" (ibid) configurando nuevas formas de percepción social.

Esta visión de la cultura como un locus formado por una pluralidad de interacciones que no se integran, como un puzle que no se resuelve en unidad ni en antítesis irreductibles (las que suspende sin borrar), desplaza la atención del usuario y del lector a las partes, a los indicios objetivos, a los fantasmas intersubjetivos, a los eslabones que integran la secuencia que compone cada práctica ${ }^{32}$. Despliega como diorama instantáneo, aunque fragmentado, la experiencia cotidiana que conocemos y vivimos como "caja negra". El efecto de este modo de cronicar es doble: a nivel cultural hace visible las operaciones invisibles que componen cada práctica; a nivel lector suscita espacios inéditos de articulación del deseo.

* Artículo derivado de los Proyectos FONDECYT 1160230 (Investigador responsable) y FONDECYT 1181787 (Co-investigador).

\footnotetext{
${ }^{32}$ Preguntándose, incluso, por la determinación que le cabe a "los inventos derivados de la electricidad" en las operaciones semióticas e históricas que configuran a la obra artística, tanto como a nuestra percepción y goce de ella. Estas consideraciones de JEB anteceden el célebre estudio en que Walter Benjamin reflexiona sobre la incidencia de la reproductibilidad técnica en la percepción y función histórico-política de la obra de arte. Este estudio de Benjamin data de 1936. Las crónicas de JEB que estudiamos van desde 1921 a 1935.
} 
Dossier. Roberto Hozven. "Patrimonialismo y casuismo, puerto y ‘santiaguinería’, en las crónicas ensayísticas de Joaquín Edwards Bello".

\section{REFERENCIAS}

Alvarado Cornejo, Marina, "Ni aristócratas, ni rebeldes, ni tristes ni contentos: Escritura y Revistas Literarias de Joaquín Edwards Bello, Teresa Wilms Montt y Vicente Huidobro". Revista Literatura y Lingüística 21 (2010): 29-44.

Barthes, Roland. "Bernard Faucon". 1978. Oeuvres completes V. Livres, textes, entretiens 1977-1980. Édition revue, corrigée et présentée par Eric Marty. Paris: Seuil, 2002. 471-474.

."Proxéme. 20 abril 1977". Comment vivre ensemble. Simulations romanesques de

quelques espaces quotidiens. Cours et séminaires au Collège de France (1976-1977). Texte établi, annoté et presenté par Claude Coste. Paris: Seuil / IMEC, 2002: 155-165.

Roland Barthes par lui-même. Paris: Seuil, 1975.

Benjamin, Walter. "Sur le concept d'histoire". 1942. Oeuvres III. Traducción del alemán Maurice de Gandillac, Rainer Rochlitz y Pierre Rusch. París: Gallimard, 2000. 427 443.

Bobbio, Norberto; Matteucci, Nicola y Gianfranco Pasquino, directores. Diccionario de política l-z. 1976. José Arico, Martí Soler y Jorge Tula, redactores de la edición española. México: siglo XXI editores, 1998.

Cariou, Pierre. "Casuistique". Monique Canto-Sperber. Dictionnaire d'éthique et de philosophie. Paris: PUF, 2001. 209-221.

Chemama, Roland. Diccionario del psicoanálisis. 1998. Bajo la dirección de Roland Chemama y Bernard Vandermersch. Traducción de Teodoro P. Lecman e Irene Agoff. Argentina: Amorrortu, 2004. 2a ed.

Costa Lima, Luiz. "Chapter Four. Literature and Society in Hispanic America: Nineteenth and Early Twentieth Centuries". The Dark Side of Reason. Fictionality and Power. Translated by Pablo Henriques Britto. Stanford, CA: Stanford University Press, 1992. 110-185.

De Certeau, Michel. The Practice of Everyday Life. 1980. Traducción de Steven F. Rendall. Berkeley/ Los Angeles/ London: University of California Press, 1984.

De Neuter, Patrick, "Fantasma [Fantasía24]". En Chemama, Roland. Diccionario del psicoanálisis. 248-252, n. 24.707.

Edwards Bello, Joaquín. Crónicas. Volumen IV (1934-1935). Edición de Roberto Merino. Prólogo de Cecilia García-Huidobro. Santiago: Ediciones Universidad Diego Portales, 2012.

- Crónicas. Volumen III (1931-1933). Edición de Roberto Merino. Prólogo de Manuel Vicuña. Santiago: Ediciones Universidad Diego Portales, 2011.

. Crónicas. Volumen II (1926-1930). Edición de Roberto Merino. Prólogo de Héctor Soto. Santiago: Ediciones Universidad Diego Portales, 2009.

. Crónicas. Volumen I (1921-1925). Edición y prólogo de Roberto Merino. Santiago: Ediciones Universidad Diego Portales, 2008.

Freud, Sigmund. La interpretación de los sueños (Primera parte). Volumen 4 (1900). Ordenación, comentario y notas de James Strachey. Traducción de José L. Etcheverry Buenos Aires/ Madrid: Amorrortu Editores, 2007.

Geertz, Clifford. The Interpretation of Cultures. New York: Basic Books, 1973.

Godzich, Vlad. "The Further Possibility of Knowledge". Michel de Certeau. Heterologies. Discourse on the Other. 1978-1980. Minneapolis: University of Minnesota Press, 1986. vii-xxi. 
Nueva Revista del Pacífico 2020, № 72, (214-238). ISSN (e) 0719-5176

Góngora, Mario. Estudios sobre la historia colonial de Hispanoamérica. 1975. Traducción de Gonzalo Rojas Sánchez y Marcia Dawes Carrasco. Santiago: Edit. Universitaria, 1998.

Habermas, Jürgen. The Structural Transformation of the Public Sphere: an Inquiry into a Categorie of Bourgeois Society. 1962. Trad. inglesa Berg Publishers. Cambridge, Massachusetts: MIT Press, 1989

Kosellek, Reinhart. Critique and Crisis. Enlightenment and the Pathogenesis of Modern Society. 1959. Trad. inglesa Berg Publishers. Cambridge. Massachusetts: The MIT Press, 1988.

Lacan, Jacques. Le séminaire. Livre II. Le moi dans la théorie de Freud et dans la technique de la psychanalyse. Texto establecido por Jacques-Alain Miller. Paris: Seuil, 1978.

Lastarria, José Victorino. Investigaciones sobre la influencia social de la conquista y del sistema colonial de los españoles en Chile. Universidad de Chile. Discurso de apertura del año académico 1844 . Web.

Lechner, Norbert. Las sombras del mañana. La dimensión subjetiva de la política. Santiago: LOM, Colección Escafandra, 2002.

Lévi-Strauss, Claude. El pensamiento salvaje. 1962. Traducción de Francisco González A. México/ Buenos Aires, 1964.

Melfi, Domingo. "Sin brújula". 1933. Páginas escogidas. Selección y prólogo de Alfonso Calderón. Santiago: DIBAM/ Editorial Universitaria, 1993. 11-59.

Menéndez y Pelayo, Marcelino. "Chile". Historia de la poesía hispanoamericana. Tomo II. 1915. Ed. de Enrique Sánchez R. Alicante: Biblioteca Virtual Miguel de Cervantes, 2008. 219-300.

Mistral, Gabriela. "Cordillera". Poema de Chile. Texto revisado por Doris Dana. Santiago Buenos Aires/ México/ Barcelona: Pomaire, 1967. 123-127. "Joaquín Edwards Bello" 1935. Atenea 419 (enero-abril 1968): 7-10.

Molloy, Sylvia. Acto de presencia. La escritura autobiográfica en Hispanoamérica. 1991. Trad. J. Calderón, rev. y corr. Autora, J. Chalmers y E. Grosman. México: F.C.E., 1996.

Monsiváis, Carlos. "Prólogo/ Y llegaron los aztecas que venían de Aztlán al lago de Tenochtitlan, y aguardaron los signos de la profecía, y allí junto al nopal y el águila y la serpiente, ya los esperaba una muchedumbre de reporteros y cronistas". 1980. A ustedes les consta. Antología de la crónica en México. México: Ediciones ERA, 2006. 13-127.

Morales, Leonidas, "Joaquín Edwards Bello: crónica y crítica de la vida cotidiana chilena". Revista chilena de literatura 74 (Abril 2009): 57-78.

Morse, Richard. Resonancias del Nuevo Mundo. Cultura e Ideología en Latina. 1989. Prólogo de Enrique Krause. Traducción de Jorge Brash. México: Editorial Vuelta, 1995.

. El espejo de Próspero. Un estudio de la dialéctica del Nuevo Mundo. Traducción de Stella Mastrangelo. México/ Madrid/ Argentina/ Colombia: siglo XXI, 1982.

Oyarzún, Luis. Diario íntimo. Edición póstuma. Prólogo de Leonidas Morales T. Santiago de Chile: Serie Documentos, Facultad de Ciencias Físicas y Matemáticas, Departamento de Estudios Humanísticos, Universidad de Chile, 1995. 
Dossier. Roberto Hozven. "Patrimonialismo y casuismo, puerto y 'santiaguinería', en las crónicas ensayísticas de Joaquín Edwards

Paz, Octavio. "Alba de la libertad” 1990. VI. Piezas de convicción. Obras completas 9. Ideas y costumbres I. La letra y el cetro. Edición del autor. Barcelona/ México: Círculo de Lectores/ F.C.E., 1995. 467-472.

Ruíz, Raúl. Diario. Notas, recuerdos y secuencias de cosas vividas. Volumen I 1993-2001. Selección, edición y prólogo de Bruno Cuneo. Santiago: Edics. de la Universidad Diego Portales, 2017.

. Diario. Notas, recuerdos y secuencias de cosas vividas. Volumen II 2002-2011. Selección, edición y prólogo de Bruno Cuneo. Santiago: Edics. de la Universidad Diego Portales, 2017.

Soto, Héctor, “Local y visita: el doble eje de Joaquín Edwards Bello". Estudios Públicos 118 (otoño 2010): 334-351.

Stoetzer, Carlos. Las raíces escolásticas de la emancipación de la América española. Madrid: Centro de estudios constitucionales, 1982.

Véliz, Claudio. La tradición centralista de América Latina. Barcelona: Editorial ARIEL, 1984.

Weber, Max. Economía y sociedad. Esbozo de sociología comprensiva. 1922. Johannes Winckelmann. Nota preliminar de José Medina Echeverría. Traducción de J. Medina E. y otros. México: F.C.E., 1997.

Žižek, Slavoj (comp.) "El espectro de la ideología". Traducción de Mariana Podeti. Ideología. Un mapa de la cuestión. 1994. México: F.C.E., 2003. 7-42. 